\title{
A test to measure knowledge of farmers about drip irrigation system
}

S.D. PARMAR, H.B. SHAKYA, V.B. PATEL AND G.N. THORAT

Received : 23.07.2016; Accepted : 27.09.2016

See end of the Paper for authors' affiliation

Correspondence to :

\section{S.D. PARMAR}

Extension Education

Institute, Anand Agriculture

University, ANAND (GUJARAT)

INDIA

Email : sunilextensioneducation

@gmail.com,

pontingsunil@yahoo.co.in
- KEY WORDS : Knowledge test, Drip irrigation system (DIS), Item difficulty index (p), Discrimination index $\left(\mathrm{E}^{1 / 3}\right)$, Biserial correlation, Representative of the test

\footnotetext{
- HOW TO CITE THIS PAPER : Parmar, S.D., Shakya, H.B., Patel, V.B. and Thorat, G.N. (2016). A test to measure knowledge of farmers about drip irrigation system. Internat. J. Agric. Engg., 9(2) : 239-243, DOI: 10.15740/HAS/IJAE/9.2/239-243.
}

A standardized test as defined by Noll (1957) is one "that has been carefully constructed by experts in light of acceptable objectives or purposes, procedures for administering, scoring and interpreting score are specified in detail so that no matter was given the test or where it may be given, the results should be comparable and norms or averages for different age or status have been pre determined". Keeping this definition in view, a standardized knowledge test on drip irrigation system was developed with the help of following techniques:

\section{Item selection :}

The content of the text consisted of questions called items. The important factors considered in collecting items for knowledge test was to determine and classify the objectives to be measured by it. Items were collected by referring to the relevant literature by consulting the scientists working in Agronomy, Horticulture and Farm Engineering Department of College of Agriculture, Irrigation Department of College of Agricultural Engineering and Technology, water management project and from discussion with the extension experts. Selection of items pertaining to drip irrigation system was based on following criteria:

- Response to the items should promote thinking rather than rote memorization.

- They should differentiate well informed drip adopted farmers from less informed one and have certain difficulty value.

- The items included should cover all the area of knowledge about drip irrigation system.

With these criteria in view, 51 items were selected for the consideration of the knowledge test. Before editing of items, they were subjected to the expert scrutiny and then these items were framed in the objective form of questions to control bias, if any.

\section{Item analysis :}

The item analysis, used by Jha and Singh (1970) was carried out so as to yield three kinds of information viz., Index of item validity", "Index of item discrimination" and "Item of difficulty". The index of the item difficulty indicated the extent to which an item was difficult, while 